\title{
A Arithmética e o Método Intuitivo nos manuais escolares do ensino primário (médio e superior/complementar) no Brasil e na França no final do século XIX e início do Século XX
}

\author{
Moysés Gonçalves Siqueira Filho* \\ Valérie Legros ${ }^{* *}$
}

\begin{abstract}
Resumo
$\mathrm{O}$ artigo aborda, a partir de quatro manuais escolares, respectivamente, publicados no Brasil e na França, a presença de algumas caraterísticas do método intuitivo nas lições de aritmética apresentadas por Olavo Freire e Pierre Leyssenne, os quais procuraram colocar em suas obras os programas oficiais vigentes do ensino primário. Nesse sentido, o contexto histórico da escola primária dos referidos países, em tempos da publicação dos livros de Freire e Leyssenne, colaborou nas discussões promovidas. Portanto, apresentar as primeiras ideias de Pestalozzi sobre o método intuitivo e compreender o desenvolvimento dado por Ferdinand Buisson tornaram-se os objetivos traçados para este início de estudo, pois se na intuição sensível Buisson compartilhou das ideias de Pestalozzi, ele iria dele se distanciar ao desenvolver um trabalho inovador em duas outras áreas: a intuição intelectual e a intuição moral.
\end{abstract}

Palavras-chave: Aritmética. Manual Escolar. Método Intuitivo.

\footnotetext{
* Doutor em Educação Matemática pela Universidade Estadual de Campinas (UNICAMP). Professor do Departamento de Educação e Ciências Humanas e do Programa de Pós-Graduação em Ensino na Educação Básica da Universidade Federal do Espírito Santo (UFES).

** Docente-pesquisadora da Universidade de Limoges, França.
} 


\section{Introdução}

Os percursos da escola primária brasileira e francesa nos apresentam aspectos bastante comuns, seja na composição do livro didático, seja na aplicação de métodos e processos, advindos de exigências legislativas homologadas em períodos muito próximos. Assim sendo, a partir de quatro manuais escolares, cujos autores, Olavo Freire $^{1}$ (1922, 1926) (Cursos Médio e Complementar) e Pierre Leyssenne $^{2}$ (1908, 1914) (Cursos Médio e Superior), respectivamente do Brasil e França, procuraram explorar os conteúdos de aritmética, na escola primária, em consonância com as exigências dos programas oficiais da época, executamos um movimento em buscas de pistas acerca do emprego do método intuitivo em suas obras, baseando-nos na elaboração de categorias de análises extraídas das Conferências de Ferdinand Buisson.

A trajetória histórica da escola primária no Brasil revelou-nos transformações em diferentes segmentos da sociedade com a implantação da República em 1889. No campo educacional, pela primeira vez, em âmbito nacional, organizaram-se, sob a autoria de Benjamim Constant, as diretrizes para os ensinos primário e secundário. O Decreto $n^{\circ} 981$, de 8 de novembro de 1890, regulamentara, em 81 artigos, dispostos em nove títulos, a Instrucção Primaria e Secundaria do Districto Federal (BRASIL, 1890).

Do lado francês, temos Jules Ferry, o responsável pelo Decreto de 27 de julho de 1882, considerado o primeiro documento que, também, definiu para todo o território nacional as modalidades de organização do ensino primário em três cursos - o elementar, o médio e o superior -, bem como regulamentou a organização pedagógica e o plano de estudo das escolas primárias públicas e, portanto, gratuitas.

Baseando-nos nesses pequenos contextos, procuraremos contar uma história entre Brasil e França que nos remeta às publicações de Freire e Leyssennne, considerando as primeiras ideias de Pestalozzi sobre o método intuitivo e o desenvolvimento dado por Buisson, com o intuito de conceituar/definir características do método intuitivo, para, posteriormente, identificarmos a organização dos livros e das lições e delinear algumas discussões e reflexões. 


\section{A escola primária francesa: textos e contextos}

França, 1870. Início da Terceira República. Entretanto, os republicanos tomaram realmente o poder poucos anos depois. As primeiras leis que estabeleceram a escola primária, no interior do referido regime, emergiram a partir de 1879. Nesse mesmo ano, a lei Paul Bert, de 9 de agosto, exigiu que cada departamento ${ }^{3}$ mantivesse uma École Normale d'Institutrices ${ }^{4}$ ativa, para que a formação das professoras fosse equiparada a dos professores. Jules Ferry, ministro da Instrução Primária, tornou a escola pública gratuita em 1881 por meio da Lei de 16 de junho, e ao mesmo tempo a educação obrigatória para todas as crianças francesas, instaurando, dessa forma, seu processo de secularização (FRANÇA, 1881).

Com o apoio de alguns importantes colaboradores, entre os quais podemos mencionar Ferdinand Buisson e Octave Gréard, Jules Ferry publicou em 27 de julho de 1882, um decreto que regulamentou a organização pedagógica e o plano de estudo das escolas primárias públicas. Esse texto foi muito importante, pois foi o primeiro que definiu, para todo o território, as modalidades de organização do ensino primário em três cursos, o elementar, o médio e o superior, os programas que os professores e as professoras teriam que aplicar nas escolas, bem como abordou certos processos e métodos pedagógicos que deveriam ser utilizados por esses(as) professores(as) em sala de aula (FRANÇA, 1882).

A escola primária francesa da Terceira República, amparada pelas propostas reformistas, surgiu como a instituição responsável pela instrução e pela educação das crianças do povo francês e, para tanto, consagrou-se como popular, pública e gratuita, sendo financiada pelo Estado e pelos municípios. Entre as suas atribuições, bem estabelecidas, estavam transmitir e ensinar um mínimo de conhecimentos úteis e formar um cidadão republicano.

O Decreto de 27 de julho de 1882 especificou que, retomando as palavras de Octave Gréard (apud LIMOGES, 1899, p. 17), “o propósito da educação primária não é de aprender tudo o que é possível saber sobre as várias matérias, mas de bem aprender, para cada uma delas, o que não é permitido ignorar". Assim, os programas escolares integraram todos os conhecimentos que as crianças precisariam para suas vidas futuras. Esse programa se configurou como imponente, mas delimitado

pela utilidade do conhecimento a ser repassado aos alunos, ou seja, o que não possuia nenhuma utilidade, não teria lugar na escola primária. O pensamento pedagógico de Ferdinand Buisson já estava 
amplamente presente nas entrelinhas do Decreto em vigor por mais de quarenta anos, sendo substituído apenas em 20 de junho de 1923 pelas Instruções Oficiais, as quais estabeleceram o curso preparatório ${ }^{5}$ para além dos três cursos já existentes (elementar, médio e superior), bem como poucas mudanças nos programas de ensino em relação à versão de 1882.

\section{A escola primária brasileira: pretextos e intertextos}

Com a substituição da Monarquia pela República, em 1889, ocorreria na sociedade brasileira mudanças significativas em diferentes segmentos, não só políticos, mas também econômicos e educacionais. Nesse cenário de transformações, dentre os poucos militares que conspiraram pela República, destaca-se a participação do tenente-coronel e professor de matemática na Escola Militar Benjamin Constant, posteriormente ministro do recém-criado Ministério de Instrução Pública, Correios e Telégrafos, sobretudo na elaboração da reforma curricular do ensino primário e secundário, a primeira e mais completa, em âmbito nacional, legitimada pelo Decreto $\mathrm{n}^{\circ} 981$, de 8 de novembro de 1890 (SIQUEIRA FILHO, 2015).

A partir de então, o ensino primário, livre, gratuito e laico seria ministrado em escolas públicas de duas categorias: $1^{\circ}$ e $2^{\circ}$ graus, distintas para cada sexo. $O$ ensino do $1^{\circ}$ grau abrangeria três cursos: o elementar (para alunos de 7 a 9 anos), o médio (para os de 9 a 11) e o superior (para os de 11 a 13), os quais deveriam ser contemplados pela aplicação do methodo intuitivo e, gradualmente feito, em cada curso o estudo de todas as matérias, dentre elas: contar e calcular; arithmetica pratica até regra de tres, mediante o emprego, primeiro dos processos espontaneos e depois dos processos systematicos; systema metrico precedido do estudo da geometria pratica (tachymetria); desenho. As escolas do $2^{\circ}$ grau admitiriam alunos de 13 a 15 anos, cujas disciplinas relacionadas à Matemática se configuraram em: arithmetica (estudo complementar), algebra elementar, geometria e trigonometria (BRASIL, 1890).

Entretanto, a reforma não chegou a ser totalmente posta em prática. A permuta do currículo acadêmico por um currículo enciclopédico, com inclusão de disciplinas científicas, o que, inclusive, descaracterizava os princípios positivistas de Augusto Comte, para o qual a introdução das ciências antes dos 14 anos não era recomendada, e, portanto, defendia uma educação de caráter estético, baseada na poesia, na música, no desenho e nas línguas, que não teve êxito, haja vista a falta de apoio político das elites, que enxergavam nas ideias do reformador, muito em função da cientificidade do 
ensino, uma ameaça à formação dos jovens, cuja educação se amparava pelos valores da mentalidade da aristocracia-rural (ROMANELLI, 1978).

Posteriormente, outras reformas acabariam por se apresentar durante a Primeira República, também conhecida por República Velha (1889-1930), tais como: Reforma Epitácio Pessoa (1901), que acentuou a parte literária do currículo secundário, cuja duração passou de sete para seis anos. Até 1911, a educação no Brasil se orientou pelo código dos institutos de ensino superior e secundário, conhecido como Código Epitácio Pessoa - Reforma Rivadávia Correia (1911) -, apoiada nas ideias do ensino livre, permitiu aos estabelecimentos de ensino secundário a realização de exames reconhecidos oficialmente. Conhecida como a reforma que desoficializou o ensino no Brasil, a Reforma Carlos Maximiliano (1915), teve como objetivo melhorar a qualidade do ensino secundário e se afastou da orientação de Epitácio Pessoa, e a Reforma João Luiz Alves e Rocha Vaz (1925) deu ao ensino secundário um caráter de ensino regular e se limitou a promover a difusão do ensino primário nos Estados, de acordo com o Decreto no 16.782-A, de 13 de janeiro de 1925 (BRASIL, 1925).

Nota-se que o ensino primário não seria nelas contemplado, permanecendo a tradição do ensino elitista do Império, no qual a preocupação era com o ensino secundário e superior. Seguiram, sob esta perspectiva, as Reformas Francisco Campos (1932) e Gustavo Capanema (1942).

Efetivamente, providência, relacionadas a este nível de escolarização foram tomadas no âmbito da educação nacional, que estão explicitas na Lei Orgânica do Ensino Primário, regulamentada pelo Decreto-Lei $\mathrm{n}^{\circ}$ 8.529, de 2 de janeiro de 1946 (BRASIL, 1946), bem como nas Leis $\mathrm{n}^{\circ} 4.021$, de 20 de dezembro de 1961 (BRASIL, 1961), Lei $\mathrm{n}^{\circ}$ 5.692, de 11 de agosto de 1971 (BRASIL, 1971), Lei $\mathrm{n}^{\circ}$ 9.394, de 20 de dezembro de 1996, em vigor até os dias atuais, revogados, apenas, alguns dispositivos por outras Leis, dentre elas, a Lei $n^{0} 11.274$, de 6 de fevereiro de 2006, que acrescentou um ano ao ensino fundamental.

Contudo, a educação básica no Brasil, que compreende o antigo ensino primário, hoje os cinco primeiros anos do ensino fundamental, ainda encontra sérios problemas, seja no que diz respeito à valorização do trabalho docente, seja pela falta de visão dos governantes em relação às políticas educacionais, e embora tenha havido melhorias, a diferença ainda é grande em relação a outros países. Partimos do pressuposto de que é dever do Estado investir no professor, por ele ser o fator principal do ensino, além de ser necessária maior transparência na gestão educacional, uma vez que os dados 
educacionais que o governo produz e divulga são confusos para que a sociedade os entenda. Nesse sentido, há uma distorção sobre a real situação da qualidade do ensino básico atualmente.

\section{O método intuitivo: definições à luz de Buisson}

No cenário francês da República educadora, o método intuitivo esteve no centro das atenções e fora defendido por grandes educadores da época, entre eles, Ferdinand Buisson. Antes de sua carreira no Ministério da Instrução Pública, Buisson procurou desenvolver uma definição para o método intuitivo, baseando-se em Johann Heinrich Pestalozzi (1746-1827), considerado o primeiro pedagogo que retomou as discussões sobre intuição e tentou defini-la no campo da educação.

De acordo com os princípios pestalozzianos, a intuição “[...] não é outra coisa senão a simples presença de objetos externos perante os sentidos e o simples despertar da consciência sobre as impressões que eles produzem. É a partir dela que a natureza começa todo o ensino" (PESTALOZZI, 1898, p. 180, tradução nossa $)^{6}$. Nesse sentido, as definições deveriam ser “[...] precedidas por uma série contínua e completa de descrições do mundo exterior, passando gradualmente da intuição de cada objeto ao seu nome, do seu nome à determinação de suas propriedades, determinação que permite descrevê-lo, para finalmente poder especificá-lo, isto é, defini-lo” (PESTALOZZI, 1898, p. 198, tradução nossa) ${ }^{7}$. A intuição, assim concebida por Pestalozzi e seus colegas alemães, definiria o modo de conhecimento das coisas, o que permitiria às crianças, por exemplo, encontrar a melhor forma para perceber o mundo ao seu redor e assim apreendê-lo.

Ferdinand Buisson (1841-1932) concordou, inicialmente, com Pestalozzi no que diz respeito à "intuição sensível" ao pronunciar que "a aplicação mais comum do método intuitivo na ordem sensata é bem conhecida no ensino primário, isto é, a lição de coisas” (BUISSON, 1878, p. 453, tradução nossa $)^{8}$. De acordo com o autor, a intuição sensível deveria ser trabalhada, desenvolvida na escola, por meio de exercícios das lições de coisas, e, para tanto, as atividades deveriam ser planejadas segundo algumas etapas por ele propostas, quais sejam: “[...] ensinar às crianças, em primeiro lugar, a observar todas as coisas; depois nomeá-las; e finalmente, compará-las", ou ainda, "saber olhar, analisar, ver sob todos os ângulos, comparar e, por fim, descrever metodicamente os objetos"9 (BUISSON, 1878, p. 455, tradução nossa). Para ele, partindo das coisas para aprender com elas, tornar-se-ia mais importante do que as palavras.

PERSPECTIVA, Florianópolis, v. 34, n. 1, p. 15-40, jan./abr. 2016

http://www.perspectiva.ufsc.br 
No entanto, se na intuição sensível Buisson (1878) compartilhou das ideias de Pestalozzi, ele iria dele se distanciar ao desenvolver um trabalho inovador em duas outras áreas: a intuição intelectual e a intuição moral. Esta definida como a tomada de posse do espírito pelo coração e pela consciência de seus axiomas de ordem moral, de suas verdades indemonstráveis e indubitáveis que são como os princípios reguladores de nossa conduta. Segundo o autor, “[...] há no fundo da alma humana verdades que são simples [...]"10 (BUISSON, 1878, p. 464, tradução nossa) e que se misturam com emoções, sentimentos, influências da imaginação ou movimentos do coração.

Ao trabalhar com o conceito de intuição intelectual, Buisson (1878) acabara por ampliar as ideias apresentadas por Pestalozzi, e criou não apenas um processo adicional, mas um método autêntico, pois seu princípio fundamental considerava o respeito à natureza da criança. Para ele, "a educação dos sentidos e a educação através dos sentidos é o início do ensino intuitivo, mas ele deve, em seguida, aplicar-se aos exercícios do intelecto, aos atos de julgamento"11 (BUISSON, 1878, p. 462, tradução nossa). De acordo com Ubrich (2014, p. 35), “[...] muito mais do que os saberes, é a natureza da criança que determinará o espírito deste novo método e, assim, dar a este método a capacidade de 'animar toda a vida da escola",12. Respeitar a natureza da criança é respeitar a sua própria lógica. Crianças e adultos não têm a mesma lógica. O método intuitivo deve manter-se mais próximo da lógica da criança. "Este é precisamente o que tende o método intuitivo: ele consegue fazer a criança pensar, porque ele a deixa pensar à sua medida em vez de forçá-la a pensar à nossa, porque ele a faz andar com seu próprio passo e não com o passo do seu mestre"13 (BUISSON, 1911, tradução nossa).

Buisson (1911) refutou as aprendizagens vazias e sugeriu o que o professor deveria fazer para respeitar a lógica da criança. Antes de tudo, caberia a ele dar sentido aos saberes a aprender, oportunizando à criança trabalhar sobre conhecimentos que lhe eram significativos, isto é, sobre conhecimentos que faziam parte de seu ambiente. Tais indicações sinalizavam, ainda, outras duas: "ir do conhecido ao desconhecido", ou seja, partir do que a criança sabe para ajudá-la a descobrir coisas novas; e "ficar no concreto", "[...] a criança não se move como nós no abstrato, ela se reconhece apenas na realidade concreta, sensível, da qual ela tem alguma experiência"14 (BUISSON, 1911, tradução nossa). Demarcando outras especificidades infantis, o autor observa que:

Muito diferente é a marcha da mente infantil, que quer ir mais rápido e com alegria a partir do conhecido ao desconhecido, do concreto ao abstrato, do fácil ao difícil, ir a pulos em vez de passo a passo. A inteligência da criança é às vezes considerada como caprichosa: não é [...] ela gosta de adivinhar, descobrir, desfrutar em vez de compelir- 
se ao estudo, a desfrutar, sobretudo, da consciência de sua força e liberdade, ao sentirse agir. (BUISSON, 1911, tradução nossa) ${ }^{15}$.

De fato, o que Buisson (1911) defendia, particularmente, era que as crianças compreendessem antes de aprender. Ele criticou, fortemente, o método tradicional, que impunha às crianças decorarem uma série de conteúdos sem, necessariamente, compreendê-los. Sendo assim, o método intuitivo deveria inscrever-se em oposição a este processo.

Educar-se-ia, intuitivamente, de acordo com o que propunha Buisson (1911), sempre que se oportunizasse à criança buscar e encontrar, por si mesma, diferentes e variados caminhos para o que se lhe apresentava, mesmo que não lhe fossem mostrados objetos ou imagens, ao invés de fazê-la seguir passiva e obedientemente o seu professor ou repetir docilmente uma lição pronta. A atividade da criança foi, também, considerada pelo autor como princípio fundamental do método intuitivo, cuja aplicação deveria prever a participação ativa do processo de instrução. Sendo assim, o conhecimento teórico, abstrato, seria pouco presente, o que permitiria uma dedicação maior aos exercícios práticos. Parece-nos aqui tratar-se de "poupar preceitos e aumentar os exercícios" (BUISSON, 1878, p. 463), uma das categorias que extraímos de suas conferências e que nos auxiliou compreender a apropriação, ou não, do método intuitivo nos manuais de Freire e Leyssenne.

\section{A Arithmética Intuitiva de Olavo freire}

Ampliar, ou mesmo, delinear o que se sabe acerca de Olavo Freire (1869-1941) acaba por se tornar uma tarefa um tanto difícil, haja vista as poucas informações trazidas a seu respeito em alguns poucos textos. Por ora, nos limitamos à sua cidade natal, Rio de Janeiro, à sua profissão, pedagogo, professor da Escola Normal do Districto Federal e autor de livros didáticos. Ao lado de Menezes Vieira, diretor, e Felisberto de Carvalho, subdiretor, autores que também lecionavam em escolas cariocas, ele ocupou o cargo de Secretário-conservador na Revista Pedagógica (1890-1897), uma publicação mensal endereçada aos professores primários e promovida pelo museu pedagógico brasileiro - Pedagogium (1890-1919) - nos moldes da Revue Pedagogique (1878-1940).

A referida parceria não se restringiu tão somente à Revista Pedagógica. Juntos, a partir de 1892, diante de contratos vantajosos, transferiram - Olavo Freire com dez títulos - os direitos de suas publicações, feitas pela editora de B. L. Garnier, para a Editora Francisco Alves (BASTOS, 2000; RAZZINI, 2007). 
Data de 1908 a primeira edição do livro Arithmetica Intuitiva, distribuído em três cursos elementar, médio e complementar - em atendimento à disposição do ensino primário, àquela época, os quais totalizam 4985 atividades distribuídas entre exercícios e calculo mental, problemas escriptos e resolvidos e 299 Gravuras, cuja publicação coube à Editora Francisco Alves e Co., do Rio de Janeiro (FREIRE, 1926).

Algumas considerações, ora feitas pela imprensa local, ora por colegas, acerca de seu trabalho, foram transcritas em edições seguintes muito provavelmente como um dispositivo de valorização de suas ideias, sobretudo, sobre métodos de ensino.

Em 11 de agosto de 1908 podia se ler, por exemplo, no Vozes de Petrópolis, "Verdadeiramente agradavel e proveitoso se torna o estudo da arithmetica, feito segundo o methodo seguido pelo Sr. Olavo Freire, na sua execellente Arithmetica" (FREIRE, 1926, p. 9), ou no Jornal do Brasil, "De facto, como bem diz o qualificativo, o estudo da arithmetica torna-se, com o methodo adoptado por aquelle professor, fácil, claro ao mesmo tempo que interessante e proveitoso" (FREIRE, 1926, p. 10), ou ainda o amigo e admirador, Vargas Dantas, que em 19 de outubro do corrente ano, a ele escreve:

Li com grande satisfação o seu compendio de "Arithmetica Intuitiva" sobre cujo valor didactico é desnecessário emitir parecer. Vantajosamente conhecido em nosso magistério, é uma garantia para o publico o nome do autor, cujo brilho em nada poderia ser realçado pela recomendação de quem para isso não se julga competente. (FREIRE, 1926, p. 11).

Mas como Olavo Freire se apropriou do método intuitivo e o aplicou nos Cursos do Arithmética Intuitiva? Como ele estruturou os seus capítulos? Para nos aproximarmos de prováveis respostas a essas questões, buscaremos nos Capítulos I e IV, respectivamente, de Arithmetica Intuitiva: Curso Médio (FREIRE, 1922) e Arithmetica Intuitiva: Curso Complementar ${ }^{16}$ (FREIRE, 1926), características do método intuitivo, apoiados em algumas categorias elaboradas a partir das ideias desenvolvidas por Ferdinand Buisson $(1878,1911)$, apresentadas anteriormente, e que, basicamente, tratam da natureza e lógica da criança, de atividades que oportunizam ir do conhecido ao desconhecido, priorizam dar sentido ao saber a aprender, ou, ainda, possam permitir compreender para aprender.

O livro Arithmetica Intuitiva: Curso Médio, terceira edição (FREIRE, 1922), cuidadosamente revista, indica ter 1278 exercícios e calculo mental, 280 problemas escriptos e 29 gravuras, distribuídos 
em 208 páginas, exatamente como a primeira edição de 1908 (FREIRE, 1926), obedecendo a mesma orientação do livro antecedente - Arithmetica Intuitiva: Curso Elementar (FREIRE, 1911).

Figura 1 - Folha de rosto Arithmetica Intuitiva: Cursos Médio e Complementar, de Olavo Freire (1922, 1926)
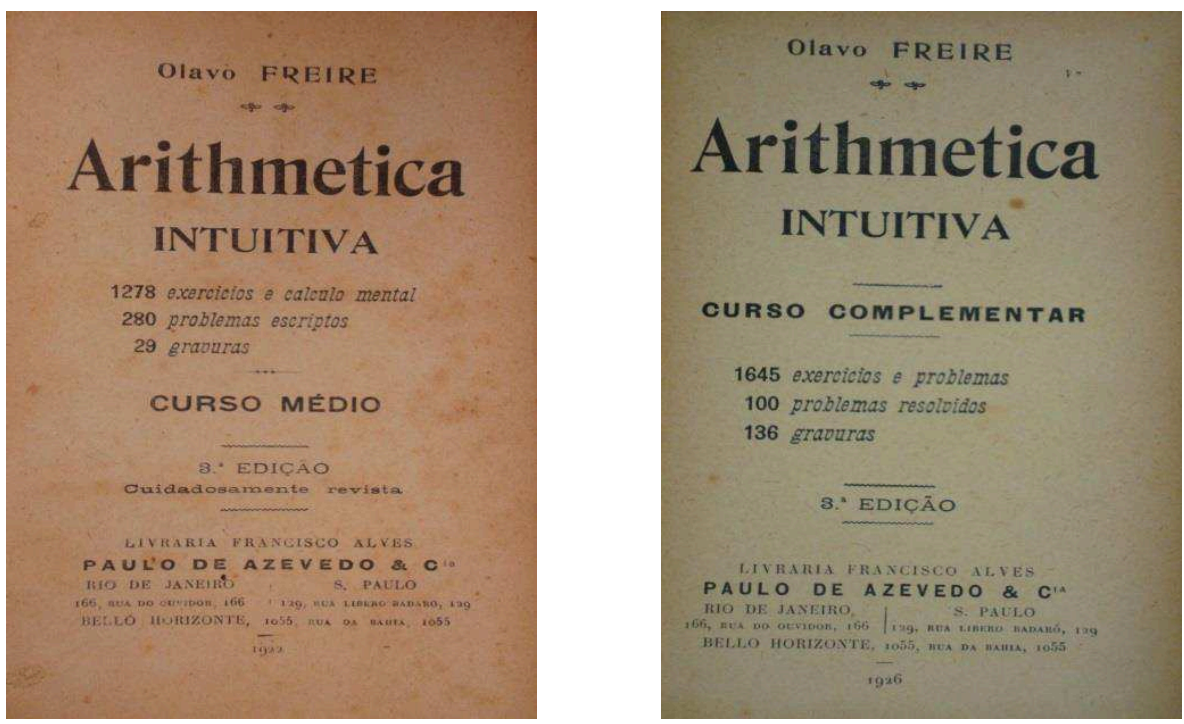

Fonte: Núcleo de Pesquisa sobre Livro e História Editorial no Brasil (LIHED), Instituto de Arte e Comunicação Social da Universidade Federal Fluminense.

O Capítulo I de Arithmetica Intuitiva: Curso Médio (FREIRE, 1922) apresenta da página 9 a 38 o estudo da divisibilidade, submúltiplo, número primo, número múltiplo, princípios da divisibilidade; caracteres de divisibilidade, prova dos noves, máximo divisor comum, meio de conhecer se um numero é primo, tabela de números primos, decomposição de um número em seus fatores primos, divisores múltiplos, mínimo múltiplo comum, fatores correspondentes, igualdade, parêntesis, colchete, e, por fim, agregam-se, da página 39 a 49, 273 Exercícios.

Como se vê, os assuntos interligam entre si e são hierárquicos, sendo desenvolvidos por meio de conceituações, problemas e exemplos. No geral, a composição do texto é iniciada pela conceituação dos primeiros assuntos indicados no sumário, necessários para os demais, posteriormente são colocadas algumas consequências/extensões, particularidades, propriedades e aplicação (teórica). Por exemplo, na página 23, o “Problema 1. Qual o m.d.c de 240 e 630?” (FREIRE, 1922). A partir desta questão, Freire (1922) desenvolve passo a passo (procedimentos) o dispositivo prático para se encontrar o máximo divisor comum de dois números, para, noutro momento - "Problema 2. Qual é o m.d.c de 191 e 79?" -, fazer a formalização do dispositivo e incluir particularidades inerentes ao tema. Por fim, na página 25, Problema 3. Qual é o m.d.c de 1440; 840 e 276? (FREIRE, 1922), generaliza escrevendo a regra. 
Isso posto, identificamos que Freire (1922), inicialmente, explica em linhas gerais o assunto em voga, descreve o passo a passo do exemplo (em busca de uma formalização), indica particularidades e, consequentemente, explicita a regra (generaliza). Conjecturamos que os exemplos e problemas são os disparadores do que se vai discutir e, portanto, representam o TODO e as regras, consequências apropriadas do que fora trabalhado, a PARTE. Tal movimento implica uma tentativa da utilização do método analítico.

Por outro lado, o autor retoma o conceito de máximo divisor comum no subitem mínimo múltiplo comum, por meio do "Problema 8. Procurar o m.d.c de 252, 268, 396 pelo processo da decomposição dos numeros em factores primos” (FREIRE, 1922, p. 32), como sendo uma das possíveis “Applicações da decomposição dos numeros em factores primos”. Freire (1922) decompõe os números, escreve seus fatores em forma de potência, conclui e formaliza a regra. O raciocínio de todo este procedimento é estendido para o "Problema 9. Procurar o m.m.c.de 12; 36 e 84 pelo processo da decomposição dos numeros em factores primos" (FREIRE, 1922, p. 33). Procede exatamente como fez anteriormente no Problema 8, entretanto, embora tenha concluído, não apresentou a regra, como que deixando para o aluno a tarefa da generalização.

Compreendemos que a atitude de Freire (1922), para esse episódio, como em outros, objetivava ensinar aos alunos observar, comparar, nomear o que se lhe apresentava, para deixar agir seus instintos intelectuais, ações essas consonantes do método intuitivo.

A esse respeito podemos destacar algumas considerações, da própria imprensa ou de amigos, veiculadas em jornais da época para a edição de 1908 e replicadas nas posteriores, como segue:

Dirigindo-se aos sentidos dos alumnos, prende-lhe logo em seguida a inteligência que sem custo, sem disso se aperceber "intuitivamente" se vae desenvolvendo no emprego das próprias armas, habituando-se assim a raciocinar com segurança de modo a por si só, mais tarde, resolver questões e problemas mais complexos; [...]. (Jornal do Brasil, 11 ago. 1908 apud FREIRE, 1926, p. 9).

[...] obriga-o desde cedo a manejar unicamente as armas que lhe oferece a sua intelligencia, preparando-o desse modo a poder mais tarde, por si só, raciocinar sobre questões mais complexas que se lhe apresentam. (Vozes de Petrópolis, 11 ago. 1908 apud FREIRE, 1926, p. 9).

[...] torna-se um estudo simples, proveitoso e agradável, com o auxilio do methodo intuitivo [...] Methodo essencial mente pratico e racional, que parte do concreto para o abstracto, do simples para o composto, do conhecido para o desconhecido, de outro não sei que melhor se adapte á inteligência e ao raciocínio dos que começam por apenas a percorrer os primeiros estádios da cultura intelectual no campo da 
mathematica. (Osorio Duque Estrada, Correio da Manhã, 14 jun. 1909 apud FREIRE, 1926, p. 12).

O Capítulo I traz, como dito anteriormente, 273 exercícios que traduzem rigorosamente todo o conteúdo na ordem que fora desenvolvido e, também, as respostas para os que exigiam algum tipo de cálculo. Uma das recomendações prescritas por Buisson (1911) é a economia de teorias e a multiplicação de exercícios, sobre o que discutiremos mais adiante. Parece-nos que a omissão de regras e demonstrações são um dos pontos fortes que diferenciava a obra de Freire das dos outros autores, conforme podemos constatar a partir dos relatos que se seguem:

A parte theorica quase inteiramente banida, as regras reduzidas ao mínimo, os numerosos exercícios e problemas graduados e afinados com a receptividade dos alunos á medida que avançam no estudo [...]. (Vargas Dantas, 19 out. 1908 apud FREIRE, 1926, p. 11).

A feitura eminentemente pratica da obra é bastante para recommenda-la: 2340 exercicios, 900 problemas escriptos, 163 gravuras ilustram o texto, em substituição ás regras e theorais de que andam empanturrados outros compêndios, por isso mesmo imprestáveis e sem os requisitos indispensáveis ao fim que se destinam. (Osorio Duque Estrada, Correio da Manhã, 14 jun. 1909 apud FREIRE, 1926, p. 12).

A ausência de regras e, sobretudo, das demonstrações que tanta repugnância despertam-nos que apenas se iniciam nesse genero de estudos; o cunho eminentemente pratico e utilitário de que se reveste todo o volume; o critério na dosagem das noções que mais convem proporcionar ao alumno; a habilidade e o tacto com que procura o livro a habituar desde logo a inteligência da creança ao raciocínio e aos processos de inducção [...]. (Osorio Duque Estrada, Correio da Manhã, 14 jun. 1909 apud FREIRE, 1926, p. 12).

[...] e isso sem fatigar a memoria com estiradas regras e definições ou extensas demonstrações. (Jornal do Brasil, 11 ago. 1908 apud FREIRE, 1926, p. 9).

Entretanto, muito provavelmente, para a edição em estudo, Freire (1926) tenha feito modificações com relação à inclusão de regras, para atender ao pedido de G. Mello e Cunha, para o qual, em 31 de janeiro de 1910, fez a seguinte consideração:

Noto, entretanto, que o autor deveria, para melhor compreensão destes exercícios, ter feito menção das regras geraes de calculo, isto é, dasregras que estabelecem a precedencia de umas operações em relação ás outras. É assim que se póde formular uma regra muito simples:

Primeiro se multiplica e se divide para depois somar ou diminuir e outras que se referem á adição e subtracção, á potenciação e radiciação, ás fracções de termos fraccionarios, etc. [...]. (MELLO E CUNHA apud FREIRE, 1926, p. 15, grifos do autor). 
Ao longo do texto da edição de 1922 encontramos, inclusive nos exercícios, algumas regras, neles postas, como notas. É o caso, por exemplo, dos exercícios 271, 272 e 273, ora transcritos:

271 Multiplique por 25 os seguintes numeros [...] - Nota 1. O numero, sendo multiplo de 4, multiplica-se a quarta parte de numero por 100. Exemplo: 8 x $25=2$ x100 = 200. Nota 2. O numero, não sendo múltiplo de 4, multiplica-se o primeiro por 100 e toma-se depois a quarta parte. Exemplo: $5 \times 25=\frac{500}{4}=125$; [...]. (FREIRE, 1922, p. 48).

272 Multiplica por 9; 19; 29; 39; 49 etc os números seguintes [...] - Nota. Diminuise o numero, de seu produto por $10,20,30,40,50,60$ etc, conforme o multiplicador fôr9 ou 19 ou 29 ou 39 etc. Exemplo: $24 \times 9=(24 \times 10)-24=240-$ $24=216 ; 37 \times 19=(37 \times 20)-37=740-37=703$; [...]. (FREIRE, 1922, p. 49).

273 Torna 125 vezes maiores os seguintes numeros [...] - Nota 1. O numero é múltiplo de 8 e nesse caso multiplica-se por 1000 a oitava parte do numero dado. Exemplo: 16 × $125=(16: 8) \times 1000=2 \times 1000=2000$. Nota 2 . O numero, não sendo múltiplo de 8 , multiplica-se primeiro por 1000 e depois toma-se lhe a oitava parte. Exemplo: $12 \times 125=(12 \times 1000): 8=12000: 8=1500$. (FREIRE, 1922, p. 49).

Chama-nos também a atenção os exercícios 119 e 148, que exigirão que os procedimentos sejam realizados diversas vezes para chegar a seus resultados, muito possivelmente, a nosso ver, é essa "repetição" que Freire (1922) considere como prática, com a qual o aluno compreende e aprende, outra categoria encontrada nas ideias de Bisson (1911). Vejamos:

Procura o m.m.c dos seguintes números [...] - 119 358; 564; 1386 e 4444 - R. 2355404436; [...]. (FREIRE, 1922, p. 43).

Procura o mínimo múltiplo comum pelo processo da decomposição em seus factores primos [...] - 148 27260; 74256; e 84942 R. 551093502960. (FREIRE, 1922, p. 44).

Com 327 páginas, o terceiro livro, Arithmetica Intuitiva: Curso Complementar (FREIRE, 1926) - cuja terceira edição é composta por 1645 exercícios e problemas, 100 problemas resolvidos, 136 gravuras -, publicado pela Francisco Alves e Co. em 1926, e com a qual trabalharemos, configura-se como continuação dos dois precedentes e contém noções de ordem mais elevada e, consequentemente, questões mais adiantadas. Vale ressaltar que esta edição não contém alterações significativas com relação à segunda edição de 1911. 
Figura 2 - Capa da segunda edição de Arithmetica Intuitiva: Curso Complementar, de 1911, de Olavo Freire

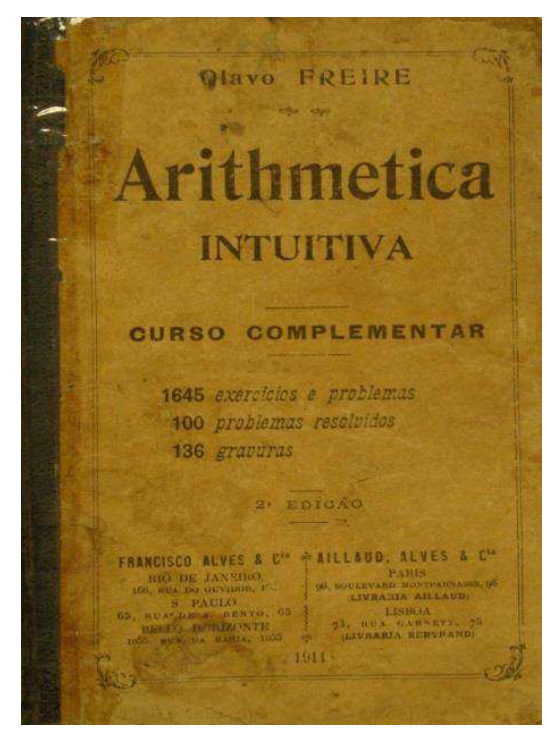

Fonte: Núcleo de Pesquisa sobre Livro e História Editorial no Brasil (LIHED), Instituto de Arte e Comunicação Social da Universidade Federal Fluminense.

O Capítulo IV, intitulado “Razões, Equidifferença, Proporções”, sumariza, da página 222 a 236, relação ou razão; razão por diferença; razão por quociente; equidifferença; proporção; quarta, terceira e media proporcional; numeros que formam proporção; achar o valor de uma quarta proporcional; achar o valor de uma media proporcional; maneiras de escrever uma proporção; grandezas diréctamente proprocionaes; idem inversamente proporcionaes; media arithmetica; e, finalizando o capítulo, 115 Exercícios em cinco páginas (FREIRE, 1926).

O modus operandi de Freire (1926 p. 232) repete-se, isto é, conceitua, exemplifica, particulariza e generaliza, deixando, por vezes, esta última tarefa a cabo do aprendiz. Assim sendo, na página 232 podemos ler: "Para achar o valor de uma media proporcional, extrai-se a raiz quadrada do producto dos extremos. Exemplo: $4: \mathrm{x}:: \mathrm{x}: 9 ; \mathrm{x} X \mathrm{x}=4 \mathrm{x} 9 ; \mathrm{x}^{2}=36 ; \mathrm{x}=\sqrt{36} ; \mathrm{x}=6$ ". Nota-se que há a introdução da incógnita $x$ e que a resolução é feita de forma direta sem mais detalhes, dando-nos a entender que o conhecimento necessário para agir nesse tipo de atividade já tenha sido adquirido em séries ou capítulos anteriores.

Mantendo-se coerente ao que fizera no livro Arithmetica intuitiva: Curso Médio, modalidade em que se encontram alunos de 9 a 11 anos, Freire (1926) nada falou acerca de operações com números negativos. Em linhas gerais, assinalou que os termos positivos seriam os precedidos do sinal $(+) e$ negativos do sinal (-). Como exemplo sugeriu a resolução da expressão aritmética [...] $8+5+16-6-$ 
$8-9+13+3+7$ da seguinte forma: "[...] somam-se todos os termos positivos, e á parte, os negativos [...] finalmente, subtrae-se a menor somma da maior: 52 - 23 = 29" (FREIRE, 1926, p. 36). Talvez essa tenha sido a razão do valor negativo de $x$ não ter sido considerado como resultado da média proporcional buscada, o que nos remete à faixa etária para este nível de escolarização, ou seja, crianças de 11 a 13 anos, segundo a legislação vigente, portanto, em respeito à natureza da criança, categoria essa, também, enfatizada por Buisson (1911) na configuração de seu método intuitivo.

Por esses e outros indicativos, previamente evidenciados, Osório Duque Estrada, acabara por recomendar, no Correio da Manhã, de 14 de junho de 1909, a obra Arithmetica Intuitiva, assim pronunciando:

O livro de Sr. Olavo freire merece ser adoptado quanto antes no curso primário de todas as escolas publicas do Brasil, onde vigoram ainda, para supplicio dos cérebros infantis, os antigos e bolorentos compêndios que tyranizam a memoria e embotam a inteligência com o emprerramento e a rotina dos velhos methodos e processos irracionais. (ESTRADA, 1909 apud FREIRE, 1926, p. 13).

Bem como, fez suas as palavras de Ramiz Galvão, cuja intenção torna pública aos seus leitores:

[...] O que pretendo é simplesmente congratular-me com o digno discipulo de Meneses Vieira, que tanto honra o nome do grande mestre, e dar um sincero aperto de mão ao laborioso Brasileiro que ainda uma vez enriquece com excellenteproducção a nossa litteratura pedagógica. (GALVÃO apud FREIRE, 1926, p. 13).

Gostaríamos, ainda, ressaltar que, como nos livros precedentes, Freire utiliza, dentre os numerosos exercícios não formulados como questões, verbos na voz imperativa: dize, procura, mostra, dá, indica, effectua, multiplica, exemplifique, explica, representa, escreve, entre outros. Esses verbos nos permitem inferir que, por meio de atividades desse tipo, intenciona fazer com que o aluno raciocine, compreenda o que está fazendo e, com isso, aprenda e dê sentido aos saberes aprendidos. $O$ que é cancellar? pergunta Freire, (1926, p. 59) e em seguida, na mesma questão: Dá synonimos desta palavra. Ou, quando comanda, na página 237: Escreve: $15: 5: \because 6: 2$ [e] Lê. O autor coloca um significado para a palavra cancelar na única nota de rodapé do capítulo, muito provavelmente para provocar a curiosidade do aluno e induzi-lo a ler tudo o que se lhe apresenta. 


\section{Leyssenne ou o desaparecimento do método intuitivo}

Pierre Leyssenne começou sua carreira como professor de Matemática. Republicano convicto, tornou-se inspetor-geral da Instrução Pública para o ensino primário e fez parte da corrente dos reformadores da escola. Colaborou na elaboração do Dictionnaire pédagogique, de Ferdinand Buisson, com o verbete intitulado Geometria, além de livros didáticos voltados para a escola primária sobre aritmética e geometria, os quais fizeram grande sucesso editorial desde as primeiras publicações no início da década de 1880, reeditados até aos anos 1940. Evidentemente, será interessante saber se Leyssenne, educador envolvido nas reflexões pedagógicas sobre a escola, assumiu o método intuitivo defendido pelos seus colegas e especialmente por Ferdinand Buisson, que o nomeou Cavaleiro da Legião de Honra em 1881.

Duas de suas obras ${ }^{17}$, La Première Année d'Arihtmétique (1908), destinado ao curso médio e composto por 144 páginas, e La Deuxième Année d'Arihtmétique (1914), destinado ao curso superior, com 410 páginas, foram aqui analisadas. Em ambas, as gravuras (Figura 3) se fizeram presentes para ajudar na compreensão dos alunos, sobre isso falaremos mais adiante.

Figura 3: Capas La Première Année d'Arithmétique, 1908 e La Deuxieme Année d'Arithmétique, 1914 - Pierre Leyssenne
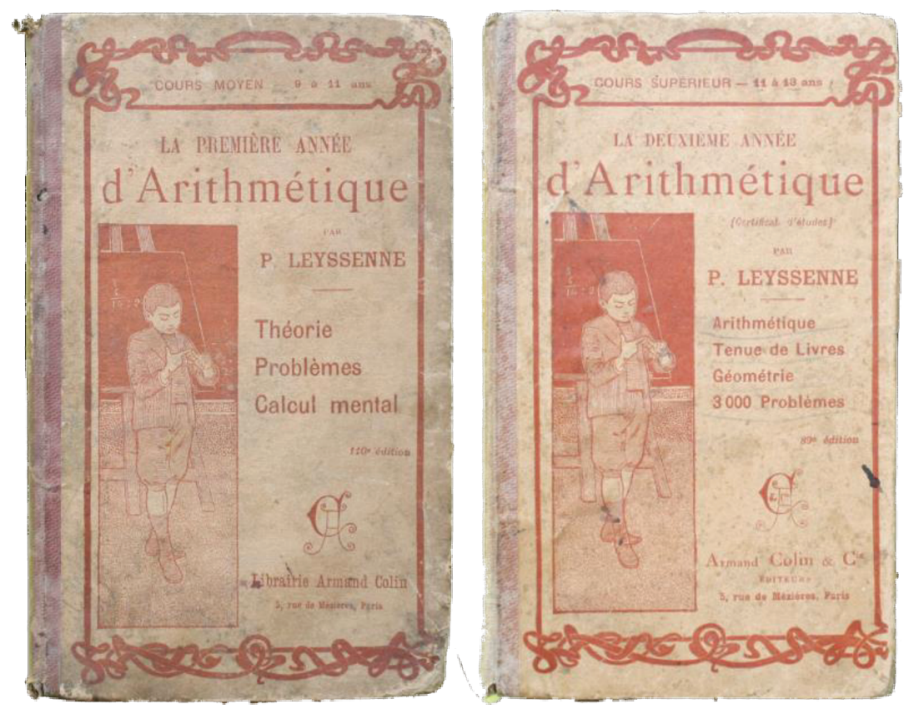

Fonte: Acervo Antigo da École Supèrieure du Professorat et l'Education (ESPE), da Académie de Limoges, França. 
Se Buisson aconselhava "poupar preceitos e aumentar os exercícios”, Leyssenne (1908, p. 4, tradução nossa) propôs a multiplicação, de uma só vez, de regras e exercícios, claramente vistos no prefácio do La Première Année de Arithmétique:

Da primeira à última página deste livro, a aplicação, de forma variada, interessante, coexiste com a regra, que descrevemos em termos simples e concisos. Vemos aparecer alternadamente o exercício escrito que chama para a reflexão e o exercício oral, que forma a memória. Por um processo particular de tipografia, as regras, impressas em caracteres bem legíveis, aparecem no topo da página; os exercícios correspondentes vêm imediatamente abaixo ${ }^{18}$.

Vale ressaltar que o livro de 1908 possui 364 "énoncés de savoir"19 (denominaremos apenas instruções), enquanto o de 1914 apresenta 877. Sob o título "a teoria", no topo da página, as instruções reúnem definições, que dizem o que são os objetos matemáticos, e regras, que especificam os procedimentos de como fazer para ler, escrever, operar e calcular ${ }^{20}$. Geralmente são acompanhadas de exemplos, "problemas orais" e questões relativas às definições e regras.

Os exercícios propõem questões diretamente relacionadas com as instruções presentes no início do capítulo e se dissociam em "exercício oral" e "exercício escrito", no La Première Année de Arithmétique, e, além destes, em "exercício teórico", no La Deuxième Année de Arithmétique. Em todos eles são acrescentados problemas que oferecem situações contextualizadas para utilizar algumas das quatro operações aritméticas. Numa mesma página, o mesmo exercício pode integrar até 18 adições ou até 45 perguntas, das quais algumas se subdividem.

Nessa maratona tendendo ao infinito, Leyssenne (1908) introduziu outra variante nas instruções, ora explicativa, ora informativa. Por exemplo, tais enunciados forneceriam aos alunos orientações sobre a necessidade de fazer adições e multiplicações rapidamente, como também, sem qualquer conteúdo matemático, o aspecto utilitário dos indicadores nas estradas, dos bancos ou dos seguros de vida.

Identificamos um primeiro desvio do modo como o autor se comportava com relação à apresentação dos conteúdos, em dois capítulos do La Premiére Année d'Arithemétique, que tratavam sobre a adição e sobre o sistema métrico. Em ambos os casos, as duas secções expõem uma estrutura idêntica ao que discutimos anteriormente. O que mudou então? A introdução prévia de alguns elementos de um determinado conteúdo. Por um lado, inserções de "aprender de cor", as quais propunham aos alunos adicionar de 3 em 3, de 7 em 7, até de 500 em 500, ou mesmo de 10.000 em 
10.000, se anteciparam ao algoritmo da adição ${ }^{21}$. Muito provavelmente isso faria com que os alunos, mesmo em se tratando de uma aprendizagem "de cor" ou de memória, compreendessem os fatos fundamentais da adição.

Por outro lado, noções e exercícios preparatórios dão os primeiros passos para o estudo do sistema métrico, cujo conteúdo, propriamente dito, é tratado, posteriormente, no capítulo VI (LEYSSENNE, 1908, p. 79.). Esse processo de preparação de um conceito por diferentes tipos de atividades, antes de sua apresentação teórica, remete-nos a um dos princípios do método intuitivo aclamados por Buisson (1911) “compreender antes de aprender”. Todavia, esses foram os dois únicos exemplos em todo o livro.

Conseguimos captar um segundo desvio, agora no La Deuxième Année d'Arithmetique, na parte dedicada ao sistema métrico, quando Leyssenne (1914) insiste na necessidade de chamar a atenção dos alunos para as diversas ferramentas de medição, especialmente as de comprimento e volume, como também na maneira de manipulá-las. Por exemplo:

Toda escola deve estar equipada com um exemplar de cada tipo das principais medidas métricas, o qual deverá ser passado para as mãos dos alunos; esta é a única maneira de deixar nos espíritos ideias específicas e lembranças duradouras. Para o metro, pode-se mostrar que dobrado ou rígido, de cobre, de madeira ou de fita, ele apresenta sempre um comprimento invariável. Medir-se-ão comprimento das mesas, paredes, as dimensões do quadro negro, etc. Traçar-se-á no quadro, no chão da sala de aula, no pátio, comprimentos iguais de 1, 2, 4 metros, etc. Mostrar-se-á o decímetro, o decâmetro, etc. ${ }^{22}$ (LEYSSENNE, 1914, p. 126, tradução nossa).

Nota-se que Leyssenne (1914) enfatiza a exploração dos objetos, atribuindo, assim, uma importância significativa na utilização do material concreto para que, com isso, o aluno aprenda. Talvez, também, tenha sido a maneira mais eficaz que encontrou para romper com a tese de que "As crianças têm dificuldade em compreender a contagem de medições de superfície e volume" (LEYSSENNE, p. 149, nota 1). No entanto, esse tipo de incentivo se limitou às atividades presentes, tão somente, nesta parte sobre o sistema métrico. Mesmo parcialmente, por meio da observação e manipulação de objetos reais, o autor retoma dois importantes princípios do método intuitivo: "ficar no concreto" e "dar sentido aos saberes a aprender".

Buisson (1911), em sua conferência sobre o método em voga, aconselhou o respeito à natureza e lógica da criança, para que eles dessem significados aos conhecimentos aprendidos. Se Leyssenne $(1908,1914)$ não faz qualquer referência à natureza da criança nos dois livros estudados, ele afirma um 
sentido utilitário dos saberes matemáticos a aprender. O autor explicita-o no prefácio do La Deuxième Année d'Aithmetique a propósito da geometria:

O ensino de geometria, tal como é praticado nas escolas primárias, se aproxima muito dos programas do ensino secundário. Assim estudado, sob um ponto de vista exclusivamente teórico, a geometria aparece aos alunos como uma ciência muito difícil, não tardando para que dela peguem aversão. No entanto, a geometria proporciona conhecimentos do maior interesse e de aplicação constante. Basta mencionar as noções de linhas paralelas, perpendiculares, ângulos, polígonos, círculos, medição de linhas, áreas e volumes, para mostrar que o marceneiro, carpinteiro, pedreiro, pintor de edifícios, até mesmo o comerciante e o agricultor precisam estudar a geometria prática. (LEYSSENNNE, 1914, p. 4, grifo nosso, tradução nossa) ${ }^{23}$.

Leyssenne (1914) insiste, particularmente, na dimensão utilitária do conhecimento matemático na geometria, mas também na aritmética, os quais se estendem para as atividades profissionais dos artesãos, agricultores ou outras profissões. Para ele, a escola deve preparar o aluno para entrar na vida profissional, indicando os conhecimentos necessários para o exercício de determinadas profissões. Essa dimensão pré-profissional é, particularmente, forte no La Deuxième Année d'Arithmétique (LEYSSENNNE, 1914), ressaltando que este livro é destinado a crianças de 11 a 13 anos e que, em breve, deixarão a escola para integrar-se no mundo do trabalho.

Assim, para autor a relação de utilidade do conteúdo de matemática é mais importante do que a abstração intelectual imposta aos alunos, o que o faz apresentar em seus livros um universo social semelhante ao do vivido pelos alunos que os utilizam. Os problemas retratam personagens artesãos, agricultores, remetendo-os às coisas da vida quotidiana do comércio, da indústria, da agricultura, elementos que fazem parte da ambiência familiar.

Outro ponto forte são as gravuras, que são mais numerosas no La Deuxième Année d'Arithmétique. Porém, em ambos, elas são utilizadas para mostrar aos alunos os objetos matemáticos presentes na geometria e no sistema métrico. Algumas delas são apresentadas em "tamanho real". Leyssenne parece ter o desejo de dar uma representação mental o mais justa possível para os alunos, o que os ajudariam na representação gráfica. A observação de materiais concretos e sua manipulação pelos alunos se inscrevem na perspectiva de um ensino com uma sólida dimensão concreta. 


\section{Considerações Finais}

A modificação da fisionomia educacional em âmbito nacional por meio de decretos, a divisão do ensino primário em Cursos elementar, médio e superior, a gratuidade e laicidade são alguns aspectos bastante comuns e significativos entre Brasil e França com relação à escola primária.

Algumas dessas semelhanças ainda são possíveis de serem verificadas nas obras que analisamos: Leyssenne $(1908,1914)$ e Freire $(1922,1926)$, por exemplo, escreveram três obras para as três etapas da escola primária e elegeram a aritmética para mote de seus trabalhos. Contudo, a análise dessas obras mostra haver alguns distanciamentos com a similaridade dos programas apresentado, o encaminhamento didático e a utilização do método intuitivo.

Assim sendo, em Freire $(1922,1926)$ o método intuitivo tornou-se mais presente no Curso médio do que no complementar. Sua proposta de trabalho para os alunos, por exemplo, parte da observação e conceituação e imbrica na generalização e formulação de regras. Parece-nos que ele entendia a hierarquia como sendo "ir do conhecido ao desconhecido" e como prática, a quantidade de exercícios e a repetição de procedimentos, não privilegiando a aplicação dos conteúdos na cotidianidade dos alunos, princípios, esses, preconizados por Buisson (1911). Apesar das gravuras aparecerem nos dois livros, pouco ou quase nada delas foram acionadas em auxílio à compreensão do aluno.

Em Leyssenene $(1908,1914)$, a presença do método intuitivo se mostrou bastante evanescente, nas duas obras analisadas. Sua abordagem didática propõe, constantemente, partir da teoria para os exercícios de aplicação. As únicas variações aconteceram em algumas atividades que anteciparam, prepararam a apresentação da lição (Curso Médio) ou prescreveram a observação e manipulação de objetos concretos (Curso Superior).

Muito provavelmente, a ausência das características do método intuitivo, desenvolvidas por Buisson (1911), nos livros escolares de aritméticas nos Cursos Médio e Superior de Leyssenne (1908, 1914) se deve à sua significativa utilização para introduzir as quatro operações, no seu Anné Préparatoire d'Arithmétique (antes de 1893), destinado ao Curso Elementar. Assim, parece-nos que, para autor, o emprego do método intuitivo seja mais importante para as crianças mais jovens, do que para as mais velhas.

Como já dito, há uma distância, uma menor utilização do método intuitivo por Freire (1922, 1926) entre o curso médio e complementar. Essa desconexão é, também, perceptível em Leyssenne 
(1908, 1914), mas entre os cursos elementar (LEGROS; SIQUEIRA, 2015) e médio. Nos dois autores o método intuitivo incide mais sobre os estudantes jovens do que nos de mais idade. Seria o método intuitivo mais eficaz para as crianças? Hipótese essa também formulada pelo prório Buisson (1911).

Leyssenne escreveu seus livros nos anos 1880 (reimpressos muitas vezes), no mesmo período em que Buisson desenvolvia o seu método intuitivo. Por outro lado, Freire publicou um pouco mais tarde e, muito provavelmente, por uma segunda hipótese, tenha se beneficiado de uma reflexão um tanto mais apurada sobre o método intuitivo.

Podemos igualmente questionar sobre o desembarque do método intuitivo no Brasil, isto é, os autores que importaram esse método desfrutaram de um contexto mais ou menos favorável para impôlo em seus livros didáticos? Além disso, a proximidade, pouca ou muita, dos autores de manuais escolares de aritméticas com instâncias dirigentes ou pensadores desse método pedagógico influenciou sua utilização em suas publicações?

Essas questões abrem caminhos para outras investigações e permitem, por exemplo, verificar como outros professores-autores, contemporâneos ou não, de Freire e Leyssenne se apropriaram dométodo intuitivo na estruturação de seus livros didáticospara alunos do ensino primário.

\section{Notas}

${ }^{1}$ Nascido no Rio de Janeiro em 1869, pedagogo, professor da Escola Normal do Districto Federal e autor dos livros didáticos Arithmetica Intuitiva (1 ${ }^{\text {a }}$ edição, 1908), Desenho Geométrico e Noções de Geometria (1894, a 41 a edição data de 1946) e Primeiras Noções de Geometria Prática. Ocupou o cargo de secretário-conservador, ao lado de Menezes Vieira (Diretor) e Felisberto de Carvalho (Subdiretor). Publicou mensalmente na Revista Pedagógica, em circulação de 1890 a 1897, que era endereçada aos professores primários. Freire faleceu em 1941, aos 72 anos de idade (SIQUEIRA FILHO, 2015).

${ }^{2}$ Nasceu em Saint-Germain-les-Belles (Haute-Vienne) em 27 de setembro de 1827. Professor de Matemática e inspetor geral do ensino primário (1880). Autor de La Prémiére année d'arithmétique (calcul écrit et oral), 1884, e La deuxiéme année d'arithmétique, 1886, ambos destinados às escolas primárias. Faleceu em Paris em 14 de desembro de 1916 (LEGROS; SIQUEIRA FILHO, 2015).

${ }^{3}$ Divisão territorial: existiam na época 90 departamentos na França metropolitana.

${ }^{4}$ Instituição responsável pela formação de professoras.

${ }^{5} \mathrm{O}$ curso preparatório é uma classe de um ano que antecede o curso elementar e que recebe as crianças a partir dos seis anos de idade.

6 “[...] n'est pas autre chose que la simple présence des objets extérieurs devant les sens et le simple éveil de la conscience des impressions qu'ils produisent. C'est par elle que la nature commence tout enseignement" (PESTALOZZI, 1898, p. 180).

7 “[...] il faut absolument que les définitions soient précédées d'une série continue et complète de descriptions du monde extérieur, passant graduellement de l'intuition de chaque objet à sa dénomination, 
de sa dénomination à la détermination de ses propriétés, détermination qui permet de le décrire, pour arriver enfin à pouvoir le préciser, c'est-à-dire le définir" (PESTALOZZI, 1898, p. 198).

8 "L'application la plus ordinaire de la méthode intuitive dans l'ordre sensible est bien connue dans l'enseignement primaire, c'est la leçon de choses" (BUISSON, 1878, p. 453).

9 "[...] d'apprendre aux enfants avant tout à observer les choses; puis à les nommer; enfin et par là même à les comparer"; ou encore: "[...] savoir regarder, analyser, voir sous toutes les faces, comparer et enfin décrire méthodiquement les objets" (BUISSON, 1878, p. 455).

10 "Là aussi, Messieurs, il y a matière à intuition ; là aussi, il y a au fond de l'âme humaine des vérités qui sont simples et que nous demandons à l'instruction primaire de faire saisir aussi bien que les vérités de sens commun et les réalités sensibles" (BUISSON, 1878, p. 464).

11 "L'éducation des sens et l'éducation par les sens est bien le commencement de l'enseignement intuitif, mais il faudra qu'il s'applique ensuite aux exercices de l'intelligence, aux actes du jugement" (BUISSON, 1878, p. 462).

12 "bien plus que les savoirs, c'est la nature de l'enfant qui va déterminer l'esprit de cette nouvelle méthode et, par là même, donner à celle-ci la capacité 'd'animer toute la vie de l'école'" (UBRICH, 2014, p. 35).

13 "C'est précisément ce à quoi tend la méthode intuitive : elle parvient à faire penser l'enfant parce qu'elle le laisse penser à sa façon au lieu de le contraindre à penser à la nôtre, parce qu'elle le fait marcher de son propre pas et non du pas de son maître" (BUISSON, 1911).

14 "[... ['enfant ne se meut pas comme nous dans l'abstrait, il ne se reconnait bien que dans les réalités concrètes, sensibles, dont il a quelque expérience" (BUISSON, 1911).

15 "Tout autre est la marche de l'esprit enfantin, qui veut aller vite et joyeusement du connu à l'inconnu, du concret à l'abstrait, du facile au difficile, plutôt par bonds que pas à pas. On a dit quelquefois que l'intelligence de l'enfant est capricieuse : elle ne l'est pas [...] elle aime à deviner, à découvrir, à jouir de l'étude au lieu de s'y astreindre, à jouir surtout de la conscience de sa force et de sa liberté, à se sentir agir" (BUISSON, 1911).

${ }^{16}$ Os exemplares com os quais trabalhamos foram localizados no Núcleo de Pesquisa sobre Livro e História Editorial no Brasil (LIHED) do Instituto de Arte e Comunicação Social da Universidade Federal Fluminense (UFF), sob a coordenação do Professor Dr. Aníbal Francisco Alves Bragança.

${ }^{17}$ Estes livros estão localizados no Acervo Antigo da École Supèrieure du Professorat et l'Education (ESPE) da Académie de Limoges/França

18 "De la première à la dernière page de ce livre, l'application, sous une forme variée, intéressante, côtoie la règle, que nous exposons en termes faciles et concis. On y voit figurer alternativement l'exercice écrit qui appelle la réflexion et l'exercice oral qui forme la mémoire. Par un procédé particulier de typographie, les règles, imprimées en caractères très lisibles, tiennent le haut de la page ; les exercices qui y correspondent viennent immédiatement au-dessous" (LEYSSENNE, 1908, p. 4).

${ }^{19}$ Instruções que teorizam, definem ou apresentam regras práticas (LEGROS, 2013, p. 197).

${ }^{20}$ Por exemplo: "A adição é uma operação que visa recolher vários números em um. O resultado da adição é chamado de soma ou total” (LEYSSENNE, 1908, p. 26).

${ }^{21}$ Não notamos esta tentativa no estudo das outras três operações.

22 "Toute école doit être pourvue d'un exemplaire type de chacune des principales mesures métriques, qu'on fera passer entre les mains des élèves ; c'est le seul moyen de laisser dans les esprits des idées précises et des souvenirs durables. Pour le mètre, on montrera que plié ou rigide, en cuivre, en bois ou en ruban, il présente toujours une longueur invariable. On fera mesurer la longueur des tables, des murs, les 
dimensions du tableau noir, etc. On fera tracer sur le tableau, sur le plancher de la classe, dans la cour, des longueurs égales à 1, 2, 4 mètres, etc. On montrera le décimètre, le décamètre, etc." (LEYSSENNNE, 1914, p. 4)

23 "L'enseignement de la géométrie, tel qu'il est trop souvent pratiqué dans les écoles primaires, se rapproche de trop près des programmes des écoles secondaires. Ainsi étudiée à un point de vue exclusivement théorique, la géométrie apparaît aux élèves comme une science très difficile, qu'ils ne tardent pas à prendre en aversion. Cependant la géométrie offre des connaissances de la plus grande utilité et d'une constante application. Il suffit de citer les notions relatives aux lignes parallèles, aux perpendiculaires, aux angles, aux polygones, au cercle, à la mesure des lignes, des surfaces et des volumes, pour montrer que le menuisier, le charpentier, le maçon, le peintre en bâtiments, le commerçant même et l'agriculteur ont besoin d'étudier la géométrie pratique" (LEYSSENNNE, 1914, p. 4).

\section{REFERÊNCIAS}

BASTOS, Maria Helena Câmara. Ferdinand Buisson no Brasil: pistas, vestígios, e sinais de suas idéias pedagógicas (1870-1900). História da Educação, Pelotas, RS, v. 4, n. 8, p.79-109, 2000.

BUISSON, Ferdinand. Conférence sur l'enseignement intuitif (31 août 1878, faite aux instituteurs délégués à l'exposition universelle de 1878). Revue pédagogique, Paris, p. 447-468, 1878.

BUISSON, Ferdinand. Intuition et méthode intuitive. In: BUISSON, Ferdinand. Dictionnaire pédagogique de Ferdinand Buisson. Paris: Libraire Hacchette, 1911.

BRASIL. Decreto $n^{\circ}$ 981, 8 de novembro de 1890. Approva o Regulamento da Instrucção Primaria e Secundaria do Districto Federal. Coleção de Leis do Brasil, Rio de Janeiro, 1890.

BRASIL. Decreto no 16.782-A, de 13 de janeiro de 1925. Estabelece o concurso da União para a diffusão do ensino primario, organiza o Departamento Nacional do Ensino, reforma o ensino secundário e superior e dá outras providencias. Diário Oficial da União, Brasília, DF, 7 abr. 1925.

BRASIL. Decreto-Lei n ${ }^{\circ}$ 8.529, de 2 de janeiro de 1946. Lei Orgânica do Ensino Primário. Diário Oficial da União, Rio de Janeiro, 4 jan. 1946.

BRASIL. Lei n ${ }^{\circ}$ 4.024, de 20 de dezembro de 1961. Fixa as Diretrizes e Bases da Educação Nacional. Diário Oficial da União, Brasília, DF, 27 dez. 1961.

BRASIL. Lei ${ }^{\circ} 5.692$, de 11 de agosto de 1971 Fixa Diretrizes e Bases para o ensino de $1^{\circ}$ e $2^{\circ}$ graus, e dá outras providências. Diário Oficial da União, Brasília, DF, 12 ago. 1971.

BRASIL. Lei n ${ }^{\circ}$ 9.394, de 20 de dezembro de 1996. Estabelece as diretrizes e bases da educação nacional. Diário Oficial da União, Brasília, DF, 23 dez. 1996. 
BRASIL. Lei n ${ }^{0} 11.274$, de 6 de fevereiro de 2006. Altera a redação dos arts. 29, 30, 32 e 87 da Lei no 9.394, de 20 de dezembro de 1996, que estabelece as diretrizes e bases da educação nacional, dispondo sobre a duração de 9 (nove) anos para o ensino fundamental, com matrícula obrigatória a partir dos 6 (seis) anos de idade. Diário Oficial da União, Brasília, DF, 7 fev. 2006.

FRANÇA. Loi du 16 juin 1881. Établissant la gratuité absolue de l'enseignement primaire dans les écoles publiques. Journal Officiel, Paris, juin 1881.

FRANÇA. Arrêté du 27 juillet 1882. Réglant l'organisation pédagogique et le plan d'études des écoles primaires publiques. Journal Officiel, Paris, 2 août 1882.

FREIRE, Olavo. Arithmetica Intuitiva: Curso Médio. 3. ed. Rio de Janeiro: Francisco Alves, 1922.

FREIRE, Olavo. Arithmetica Intuitiva: Curso Complementar. 3. ed. Rio de Janeiro: Francisco Alves, 1926.

LEGROS, Valérie. Des exercices de calcul à l'arithmétique en riant. Les mathématiques dans l'enseignement primaire : programmes et manuels sous la IIIe République. In: BARBIN, Évelyne; MOYON, Marc (Coord.). Les ouvrages de mathématiques dans l'histoire: entre recherche, enseignement et culture. Limoges: PULIM, 2013. p. 189-203.

LEGROS, Valérie; SIQUEIRA FILHO, Moysés Gonçalves. La méthode intuitive et l'enseignement de l'arithmétique au tournand du $20^{e}$ siècle, au Brésil e en France: le cas des manuels d'Olavo Freire et Pierre Leyssenne pour cour élémentaire des écoles primaires. Limoges: Presses Unversitaires de Limoges, 2015. (Collection Savoir scientifiques et Pratiques d'Ensignement).

LEYSSENNE, Pierre. La Première Année d'Arihtmétique. Paris: Armand Colin, 1908.

LEYSSENNE, Pierre. La Deuxième Année d'Arihtmétique. Paris: Armand Colin,1914.

LIMOGES. Organisation pédagogique et plan d'études des écoles primaires élémentaires. Limoges: Plainemaison, 1899.

PESTALOZZI, Johann Heinrich. Comment Gertrude enseigne ses enfants. Traduction d'Eugène Darin. Paris: CH. Delagrave, 1898.

RAZZINI, Marcia P. G. Livro didático e expansão escolar em São Paulo (1889-1930). Língua Escrita, São Paulo, n. 1, jan./abr. 2007.

SIQUEIRA FILHO, Moysés Gonçalves. A Revue Pédagogique: um breve ensaio em dois tempos em França dos oitocentos. In: SEMINÁRIO TEMÁTICO SABERES ELEMENTARES MATEMÁTICOS DO ENSINO PRIMÁRIO (1890 - 1971): o que dizem as revistas pedagógicas?, 12., 2015, Curitiba. Anais... Curitiba, PR: PUC/PR, 2015. p. 705-716.

ROMANELLI, Otaiza de Oliveira. História da Educação no Brasil (1930/1973). Petrópolis, RJ: Vozes, 1978. 
UBRICH, Gilles: La méthode intuitive de Ferdinand Buisson: histoire d'une méthode pédagogique oubliée. Paris: L'Harmattan, 2014. 
The Arithmetic and the Intuitive Method in textbooks of primary education (secondary and higher/complementary) in Brazil and France in the late $19^{\text {th }}$ century and early $20^{\text {th }}$ century

\begin{abstract}
The article discusses, from four textbooks, respectively, published in Brazil and in France, the presence of some intuitive method features in arithmetic lessons presented by Olavo Freire and Pierre Leyssenne, who sought to put in their works the current official programs of elementary school. In this sense, in times of the publication of Freire and Leyssenne's books, it is important to note that the historical context of primary school, of these countries, collaborated to the discussions promoted. Therefore, present the first Pestalozzi's ideas on the intuitive method and understand the development given by Ferdinand Buisson became the goals set for this early study, because, if the sensitive intuition Buisson shared of Pestalozzi's ideas, he would distance himself from it by developing an innovative work in two other areas: intellectual intuition and moral intuition.
\end{abstract}

Keywords: Arithmetic. Textbooks. Intuitive Method

\section{Moysés Gonçalves Siqueira Filho}

E-mail: siqueira.moyses@gmail.com

Valérie Legros

E-mail: valerie.legros@unilim.fr

\section{L'Arithmétique et la méthode intuitive dans les manuels scolaires d'enseignement primaire (moyen et supérieur/ complementaire) au Brésil et en France à la fin du 19e siècle et début du 20e siècle}

\section{Résumé}

L'article examine à partir de quatre manuels, respectivement publiés au Brésil et en France, la présence de certaines caractéristiques de la méthode intuitive dans les leçons arithmétiques présentés par Olavo Freire et Pierre Leyssenne, qui visait mettre dans ses œuvres les programmes officiels actuels de l'enseignement primaire. Dans ce sens, le contexte historique de l'école primaire de ces pays, au moment de la publication des livres de Freireet Leyssenne, a collaboré aux discussions promues. Donc, présenter les premières idées de Pestalozzi sur la méthode intutive et comprendre le développement donné par Ferdinand Buisson sont devenus les objectifs tracés pour ce début d'étude, car si dans l'intuition sensible Buisson a partagé des idées de Pestalozzi, il ira d'elles se distancer au développer un travail novateur sur deux autres domaines: l'intuition intellectuelle et l'intuition morale.

Mots-clés: Arithmétique. Manuels Scolaires. Méthode Intuitive.

Enviado em: 22/5/2015

Aprovado em: 8/12/2015 